\title{
Cardiac Troponin T Increased, CTCAE
}

National Cancer Institute

\section{Source}

National Cancer Institute. Cardiac Troponin T Increased, CT CAE. NCI Thesaurus. Code C143354.

A finding based on laboratory test results that indicate increased levels of cardiac troponin $\mathrm{T}$ in a biological specimen. 